Review

\title{
Farm Animal Serum Proteomics and Impact on Human Health
}

\section{Francesco Di Girolamo ${ }^{1}$, Alfonsina D'Amato ${ }^{2}$, Isabella Lante ${ }^{3}$, Fabrizio Signore ${ }^{4}$, Marta Muraca ${ }^{1}$ and Lorenza Putignani ${ }^{5,6, *}$}

1 Department of Laboratory Medicine, Bambino Gesù Children's Hospital, IRCCS, Piazza Sant'Onofrio 4, Rome 00165, Italy; E-Mails: francesco.digirolamo@opbg.net (F.D.G.); marta.muraca@alice.it (M.M.)

2 Department of Chemistry, Materials and Chemical Engineering "Giulio Natta", Politecnico di Milano, Via Mancinelli 7, Milano 20131, Italy; E-Mail: alfonsina.damato@polimi.it Department of Laboratory Medicine, San Camillo Hospital, Viale Vittorio Veneto 18, Treviso 31100, Italy; E-Mail: Isa.Lante@gmail.com

4 Department of Obstetrics and Gynaecology, San Camillo Forlanini Hospital, Circonvallazione Gianicolense, 87, Rome 00151, Italy; E-Mails: anguela@libero.it

5 Parasitology Unit, Bambino Gesù Children's Hospital, IRCCS, Piazza Sant'Onofrio 4, Rome 00165, Italy

6 Metagenomics Unit, Bambino Gesù Children's Hospital, IRCCS, Piazza Sant'Onofrio 4, Rome 00165, Italy

* Author to whom correspondence should be addressed; E-Mail: putignani.lorenza@gmail.com; Tel.: +39-06-6859-2598 (ext. 2176); Fax: +39-06-6859-2218.

Received: 26 June 2014; in revised form: 22 August 2014 / Accepted: 25 August 2014 / Published: 1 September 2014

\begin{abstract}
Due to the incompleteness of animal genome sequencing, the analysis and characterization of serum proteomes of most farm animals are still in their infancy, compared to the already well-documented human serum proteome. This review focuses on the implications of the farm animal serum proteomics in order to identify novel biomarkers for animal welfare, early diagnosis, prognosis and monitoring of infectious disease treatment, and develop new vaccines, aiming at determining the reciprocal benefits for humans and animals.
\end{abstract}

Keywords: farm animal serum proteomics; animal welfare; human health 


\section{Introduction}

Proteomics aims at identifying, quantifying, and characterizing the structure and functions of all proteins in a living organism, as well as assessing the modulation of these properties based on space, time, and physiological state.

Proteomic approaches on farm animal serum/plasma samples were applied with the purpose of certifying animal welfare in order to prevent a negative impact on human health (resulting in reciprocal benefits for humans and animals) and improve clinical management and treatment of human diseases [1] (Figure 1). Unfortunately, due to the lack of a complete characterization of animal genomes and the incomplete annotation of gene functions, studies on farm animal serum proteome are still in their infancy, compared to the fully mapped human serum proteome [2]. As shown in the next sections, to circumvent this problem, different strategies were applied by using homology searches or human annotations of BLAST-searched primary data.

Figure 1. Routinely pre-analytical and analytical approaches for farm animal serum proteomic studies. Serum samples could be pre-treated (A) to reduce the high dynamic range in protein concentration, or not pre-treated $(\mathbf{B}, \mathbf{C})$ and, subsequently, analyzed through electrophoretic, chromatographic and mass spectrometric platforms. The large amount of data produced are, then, processed by sophisticated bioinformatic algorithms for qualitative and quantitative proteomic analysis.

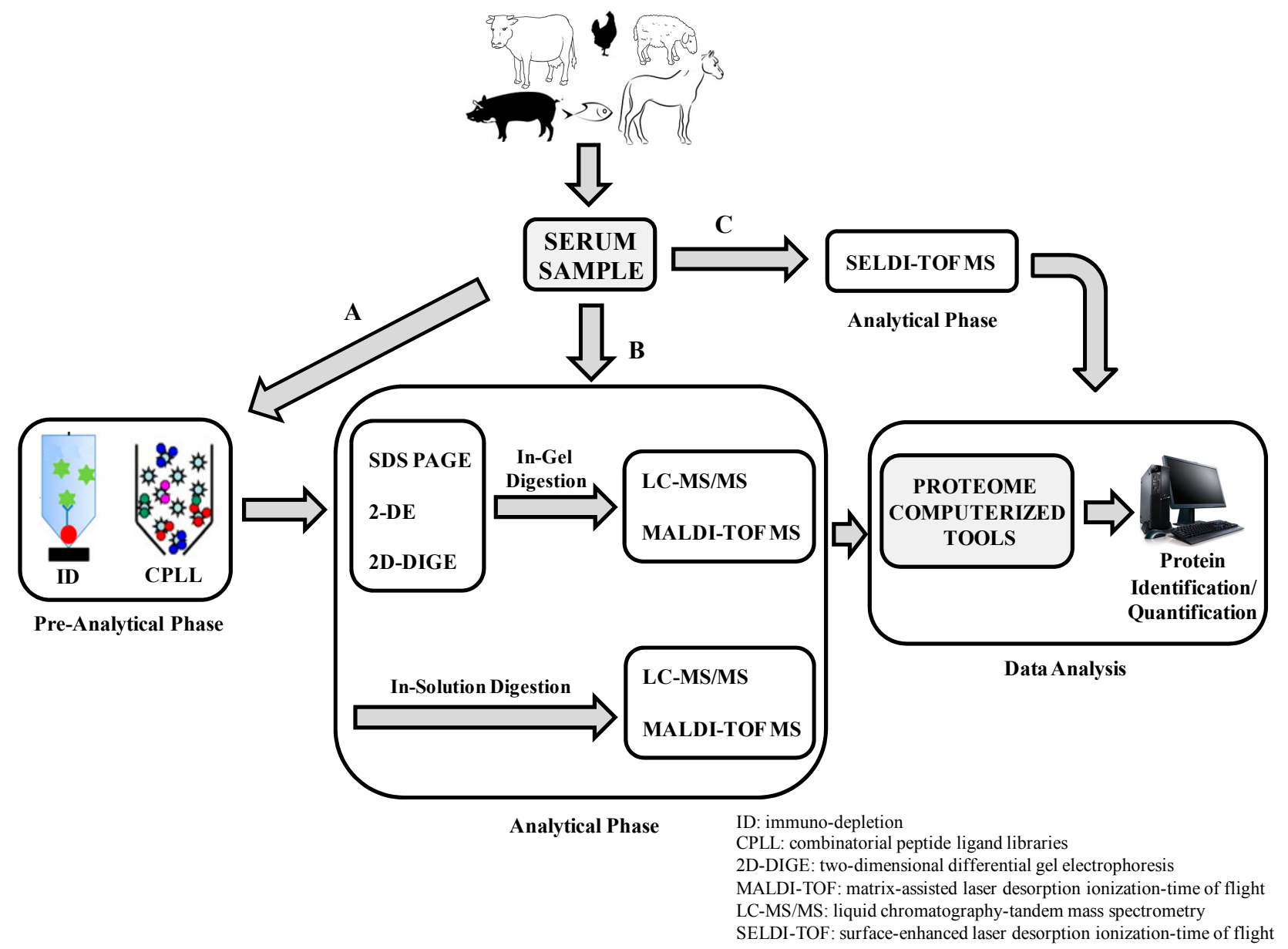


Owing to the high dynamic range of serum samples (spanning ten orders of magnitude [3]) and the limited dynamic range of the analytical instrumentations (spanning five orders of magnitude [4]), the pre-analytical phase in animal serum proteomics field could play a crucial role in reducing the differences in serum protein concentration. Therefore, two serum pre-treatment methodologies have been applied for protein immuno-depletion (ID) [5], serum proteome equalization and low-abundance protein enrichment (combinatorial peptide ligand libraries technique (CPLL)) [6-8]. More than 90\% of the serum proteome is represented by less than 10 different proteins (albumin, IgG, $\alpha 1$-antitrypsin, IgA, transferrin, etc.). Based on the high specific antibody, ID represents a very effective pre-analytical technique able to bind and remove any protein from the animal sera in a very effective manner.

The major criticisms of the ID technique are represented by the lack of suitable antibodies for all animal species and the accidental co-depletion of untargeted proteins [9]. Additionally, recent reports have strongly challenged such a protocol, stating that it might not enable access to the low-abundance proteome [10].

CPLL technique is able to significantly reduce the dynamic concentration range of the animal sera normalizing the concentration of the low-abundance proteins to those of the high abundance. Some weakness of the CPLL technique comprise the exclusion of the highly hydrophilic proteins from the capture event as well as the exclusion of other proteins designed as aberrant because they behave in an unpredictable way.

Both these techniques were successfully applied on the farm animal serum samples. The analytical phase includes proteomic approaches based on the electrophoretic, chromatographic and mass spectrometric technologies. In the field of animal serum proteomics both qualitative and quantitative methods have been applied, by using gel-based and gel-free mass spectrometry (MS) approaches.

The aim of qualitative proteomic analysis is to describe the proteins and their post translational modifications in serum samples, related to a specific patient status. The most widely used MS approach for in-depth serum protein identification is represented by the shotgun proteomics. It is a gel-free proteomic approach in which, after a total proteome enzymatic digestion, the produced peptides are separated with a high resolution liquid chromatography (LC) system and identified using tandem mass spectrometry (MS/MS) and automated database searching [11]. Qualitative analysis have also been performed by gel-based proteomic approaches, using one-dimensional (1-DE) and two-dimensional (2-DE) gel electrophoresis for protein purification and, LC-MS/MS or matrix assisted laser desorption ionization-time of flight-MS (MALDI-TOF-MS) [12] and automated database searching for a subsequent protein identification of the in-gel digested proteins.

Mass spectrometry based quantitative proteomics can be classified in relative and absolute measurements [13]. Aim of the relative quantification is establishing the modulations in protein expression between two (or more) serum proteomes (i.e., healthy versus pathological subjects).

Conversely, the absolute quantification aims at quantifying the amount of proteins/peptides into serum samples.

Animal serum proteomes have been analyzed only by using relative protein quantification approaches by: (i) gel-based platforms, 2-DE to compare spot patterns from different serum samples and two-dimensional differential gel electrophoresis (2D-DIGE) [14] to assess protein profile changes from two or three serum samples runs on a single 2D-gel; (ii) gel-free platforms represented by stable isotope based (Figure S1) and label-free methods. The first ones (ICAT [15] and iTRAQ [16], applied 
in the animal serum proteomic field, use stable isotopes to label digested proteins, introducing a mass variation between the labeled and unlabeled peptides in the process. The intensity signals obtained from the unlabeled and labeled peptide will then provide quantitative information in the MS spectrum.

Label-free methods [17] do not introduce labels and rely on chromatographic and MS data to quantify peptides in the samples. In this approach the separate LC-MS/MS runs of samples in different states are aligned and the quantitative analysis of protein concentrations is performed by calculating the area or the intensity of peaks of the same peptide in the two runs.

A very useful quantitative and qualitative MS method in the farm animal serum proteomic field is the surface-enhanced laser desorption/ionization time-of-flight (SELDI-TOF) mass spectrometry.

It combines two powerful techniques: chromatography to retain the proteins on a solid-phase chromatographic surface and MS to detect them by a TOF MS. SELDI-TOF is a profiling technique that, based on the relation between patient and control sera protein profiles, allows the identification of MS signals of potentially disease biomarkers. It represents a complementary visualization technique to 2-DE [18].

\section{Animal Genome Databases and Annotation of Gene Functions}

As mentioned above, studies on animal serum samples have to deal with the partial characterization of animal genomes and the incomplete annotation of gene functions.

The main protein sequence and Gene Ontology (GO) Annotation consortium is Uniprot-GOA that is implicated in the cure of GO annotation program [19]. An application of GO is the creation of gene product annotations, based on literature evidences or sequence-based analysis. Actually, GO Consortium (GOC) has annotated about 100 million GO terms covering $>400,000$ species, including all the kingdoms of life. This number includes two classes of GO annotations: those created manually by reviewing the literature and those generated computationally via automated methods [20]. Uniprot provides the "complete proteome" for Homo Sapiens and "partially complete proteome" for Gallus Gallus, Bos Taurus, and Sus Scrofa. These well studied model organisms represent reference proteomes in several biomedical researches.

GOC aim is the development of a unique nomenclature, describing the functional characteristics (Molecular Function, Biological Process, Cellular Component) of any gene product from any organism [21].

The number of assigned GO terms to gene products and the number of distinct protein of human and main farm animals are showed in Table 1. The annotation data in GO database should contain information about the source (protein databases) and the evidence of implication in a specific biological process. The number of terms associated to a specific organism is then strictly related to the number of entries of gene products. Only few animal databases are quite complete and this is the main limit to describe the output of proteomic analyses of animal serum related to human serum.

However, even if there are some lacks in the full description of animal proteomes, their characterization is possible thanks to the use of reference proteome databases, homology searching (BLAST searching) and to interfere the reference GOA databases with experimental animal data. One of GO's main uses is, in fact, to perform enrichment analysis on gene sets. For example, given a set of genes that are up-regulated under certain conditions, an enrichment analysis will find which GO terms are 
over-represented (or under-represented) using annotations for that gene set. There are a number of different tools that provide enrichment capabilities. Some of these are web-based, others may require the user to download an application or install a local environment. Tools differ in the algorithms they use, and the statistical tests they perform. Some other examples of enrichment tools are: gProfiler; BiNGO; Ontologizer and Cytoscape.

Table 1. Gene Ontology (GO) annotations of main farm animal species.

\begin{tabular}{ccc}
\hline GO Annotation & Number of Associations & Number of Distinct Proteins \\
\hline Human & 403,735 & 46,159 \\
Chicken & 93,784 & 14,238 \\
Cow & 128,684 & 20,032 \\
Pig & 107,097 & 19,723 \\
\hline
\end{tabular}

\section{Animal Serum Proteomic Applications}

As shown in Table 2, this article focuses on farm animal serum proteomics, aiming at determining the reciprocal benefits for humans and animals.

Table 2. Some applications of serum proteomic approaches in the veterinary field.

\begin{tabular}{|c|c|c|c|}
\hline Farm Animals & Proteomic Techniques & Serum Proteomics Study & Reference \\
\hline \multirow{8}{*}{$\begin{array}{l}\text { ingey } \\
\text { Bovine }\end{array}$} & $\begin{array}{l}\text { 2D-DIGE } \\
\text { MALDI-TOF-MS } \\
\text { MS/MS }\end{array}$ & $\begin{array}{l}\text { Serum proteomic analysis of Bruna cows to identify novel } \\
\text { potential biomarkers for stress and welfare }\end{array}$ & {$[22]$} \\
\hline & MALDI-TOF-MS & $\begin{array}{l}\text { Production of reproducible protein mass profiles able to } \\
\text { identify calves undergoing illicit treatments }\end{array}$ & [23] \\
\hline & $\begin{array}{l}\text { 2D-DIGE } \\
\text { MALDI-TOF-MS }\end{array}$ & $\begin{array}{l}\text { Investigation of new pathophysiological modulations in the } \\
\text { plasma proteome of cows affected by milk fever }\end{array}$ & [24] \\
\hline & $\begin{array}{l}2-\mathrm{DE} \\
\mathrm{MS}\end{array}$ & $\begin{array}{l}\text { Study of serum proteome modulations of heifers during the } \\
\text { last phase of pregnancy and early postpartum as a tool for } \\
\text { the most accurate management of the peripartum period of } \\
\text { these animals }\end{array}$ & {$[25]$} \\
\hline & $\begin{array}{l}\text { 1-DE } \\
\text { MALDI-TOF-MS }\end{array}$ & Identification of 480 bovine plasma proteins & [26] \\
\hline & $\begin{array}{l}\text { MALDI-TOF-MS } \\
\text { 2-DE }\end{array}$ & $\begin{array}{l}\text { Serum proteomics evaluation of cows for a better } \\
\text { understanding of mastitis pathophysiology and an early } \\
\text { diagnosis of the disease }\end{array}$ & {$[27,28]$} \\
\hline & $\begin{array}{l}\text { iTRAQ } \\
\text { MS }\end{array}$ & $\begin{array}{l}\text { Study of cattle serum samples infected with either } \\
\text { Mycobacterium bovis or Mycobacterium paratuberculosis } \\
\text { for discovery of potential biomarkers of infection and } \\
\text { progression of disease }\end{array}$ & [29] \\
\hline & $\begin{array}{l}\text { CPLL } \\
\text { 2D-DIGE } \\
\text { LC-MS/MS }\end{array}$ & Early diagnosis of bovine Johne's disease & [30] \\
\hline
\end{tabular}


Table 2. Cont.

\begin{tabular}{|c|c|c|c|}
\hline Farm Animals & Proteomic Techniques & Serum Proteomics Study & Reference \\
\hline $\begin{array}{l}\text { ingey } \\
\text { Bovine }\end{array}$ & $\begin{array}{l}\text { MALDI-TOF-MS } \\
\text { 2-DE }\end{array}$ & $\begin{array}{l}\text { Proteome and immunome of the tachyzoite stage of } \\
\text { Besnoitia besnoiti in bovine besnoitiosis to study } \\
\text { significant biological processes and host immune response } \\
\text { associated with parasite infection }\end{array}$ & [31] \\
\hline \multirow{5}{*}{ Ovine } & $\begin{array}{l}\text { 2-DE } \\
\text { MALDI-TOF-MS }\end{array}$ & $\begin{array}{l}\text { Identification of novel staphylococcal antigens for rational } \\
\text { vaccine design }\end{array}$ & [32] \\
\hline & 2-DE & $\begin{array}{l}\text { Serological proteome analysis for the identification of } \\
\text { Staphylococcus aureus antigens produced in the sheep } \\
\text { immune response during mastitis }\end{array}$ & [33] \\
\hline & $\begin{array}{l}\text { SELDI-TOF-MS } \\
1 \text {-DE } \\
\text { LC-MS/MS }\end{array}$ & Identification of biomarkers in sheep paratuberculosis & [34] \\
\hline & SELDI-TOF-MS & $\begin{array}{l}\text { Detection of a panel of } 4 \text { putative serum protein biomarkers } \\
\text { as immunological responses in infectious diseases in sheep }\end{array}$ & [35] \\
\hline & $\begin{array}{l}\text { 2-DE } \\
\text { MALDI-TOF-MS }\end{array}$ & $\begin{array}{l}\text { Application of proteomics in putative biomarker } \\
\text { discovery for early diagnosis as well as for monitoring } \\
\text { the physiological and metabolic situations critical for } \\
\text { ovine welfare }\end{array}$ & [36] \\
\hline \multirow{4}{*}{$\begin{array}{l}2 \text { Swine }_{x \rightarrow 3} \\
\text { Swine }\end{array}$} & $\begin{array}{l}\text { 2D-DIGE } \\
\text { MS }\end{array}$ & $\begin{array}{l}\text { Evaluation of the validity of traditional stress biomarkers in } \\
\text { pigs housed at different densities and identification of new } \\
\text { potential stress biomarkers }\end{array}$ & [37] \\
\hline & $\begin{array}{l}\text { 2-D-DIGE } \\
\text { MALDI-TOF-MS } \\
\text { LC-MS/MS }\end{array}$ & $\begin{array}{l}\text { Identification of } 10 \text { differentially expressed protein spots by } \\
\text { analysis of the serum proteome modulations in pigs } \\
\text { infected by CSF virus versus uninfected controls }\end{array}$ & [38] \\
\hline & LC-MS/MS & $\begin{array}{l}\text { Identification of altered pigs serum proteome with } \\
\text { FMD virus infection by analyzing the pigs before } \\
\text { and after infection }\end{array}$ & [39] \\
\hline & LC-MS/MS & $\begin{array}{l}\text { Assessment of serum proteome profiles modulation } \\
\text { between Ossabaw pigs and human NAFLD }\end{array}$ & {$[40,41]$} \\
\hline \multirow{4}{*}{$\begin{array}{l}804 \\
\text { Poultry }\end{array}$} & $\begin{array}{l}\text { 2-DE } \\
\text { MALDI-TOF-MS }\end{array}$ & $\begin{array}{l}\text { Analysis of serum proteome of hens at different } \\
\text { developmental stages as a base to explore the physiology of } \\
\text { growth or reproduction of laying hens }\end{array}$ & [42] \\
\hline & $\begin{array}{l}\text { 2-DE } \\
\mathrm{LC}-\mathrm{MS} / \mathrm{MS}\end{array}$ & $\begin{array}{l}\text { Evaluation of APEC proteome changes after exposure to } \\
\text { chicken serum to characterize specific protein molecules } \\
\text { that may be involved in serum resistance of APEC isolates }\end{array}$ & [43] \\
\hline & $\begin{array}{l}\text { 1-DE } \\
\text { MALDI-TOF-MS }\end{array}$ & $\begin{array}{l}\text { Evaluation of APEC growth in different host species } \\
\text { requires different survival strategies }\end{array}$ & [44] \\
\hline & $\begin{array}{l}\text { 2-DE, } \\
\text { MALDI-TOF-MS }\end{array}$ & $\begin{array}{l}\text { Evaluation of the serum proteome from broilers inoculated } \\
\text { with one Eimeria species }\end{array}$ & {$[45]$} \\
\hline Equine & $\begin{array}{l}\text { 1-DE } \\
\text { MALDI-TOF-MS } \\
\text { MS/MS }\end{array}$ & $\begin{array}{l}\text { Serum proteome evaluation of the effects of } \\
\text { Senecio jacobea ingestion by horses }\end{array}$ & [46] \\
\hline
\end{tabular}


Table 2. Cont.

\begin{tabular}{|c|c|c|c|}
\hline Farm Animals & Proteomic Techniques & Serum Proteomics Study & Reference \\
\hline \multirow{3}{*}{ Equine } & $\begin{array}{l}\text { MALDI-TOF-MS } \\
\text { LC-MS/MS }\end{array}$ & $\begin{array}{l}\text { Characterization of } 29 \text { different serum proteins to establish } \\
\text { a horse serum protein database and acquire a better } \\
\text { knowledge on equine proteome modulation during diseases }\end{array}$ & [47] \\
\hline & $\begin{array}{l}\text { SELDI-TOF-MS } \\
\text { MALDI-TOF-MS }\end{array}$ & $\begin{array}{l}\text { Evaluation of differences in serum proteome profiles of } \\
\text { horses, donkeys and mules to determine possible } \\
\text { metabolism-related differences }\end{array}$ & {$[48]$} \\
\hline & $\begin{array}{l}\text { 2D-DIGE } \\
\text { MALDI-TOF-MS }\end{array}$ & $\begin{array}{l}\text { Discovery of } 7 \text { potential biomarker candidates to improve } \\
\text { diagnosis and therapy of autoimmune uveitis }\end{array}$ & [49] \\
\hline \multirow{5}{*}{ Fish } & $\begin{array}{l}\text { Capillary } \\
\text { Electrophoresis-MS }\end{array}$ & $\begin{array}{l}\text { Description of the } N \text {-glycans level in serum of salmon } \\
\text { (Salmo salar) exposed to long-term handling stress }\end{array}$ & {$[50]$} \\
\hline & $\begin{array}{l}\text { 2-DE } \\
\mathrm{LC}-\mathrm{MS} / \mathrm{MS}\end{array}$ & $\begin{array}{l}\text { Assessment of the increase of lysozyme and angiotensin } \\
\text { carboxypeptidase activities in plasma of fish transferred } \\
\text { from hypoosmotic to hyperosmotic solution }\end{array}$ & {$[51,52]$} \\
\hline & $\begin{array}{l}\text { 2-DE } \\
\text { MALDI-TOF-MS }\end{array}$ & $\begin{array}{l}\text { Determination of protein profiles of alterations in serum of } \\
\text { rainbow trout (Oncorhynchus mykiss, Walbaum) as a } \\
\text { measure of the acute phase response to the probiotics } \\
\text { present in the feed }\end{array}$ & [53] \\
\hline & $\begin{array}{l}2-\mathrm{DE} \\
\mathrm{MS} / \mathrm{MS}\end{array}$ & $\begin{array}{l}\text { Characterization of the alterations in serum acute phase } \\
\text { response-related proteins with low molecular weight from } \\
\text { loach after injury }\end{array}$ & [54] \\
\hline & $\begin{array}{l}\text { 1-DE } \\
\text { MALDI-TOF-MS }\end{array}$ & $\begin{array}{l}\text { The first heterogeneous interactome between } \\
\text { shrimp serum proteins and Vibrio parahaemolyticus } \\
\text { outer membrane proteins }\end{array}$ & {$[55]$} \\
\hline
\end{tabular}

Abbreviations: MALDI-TOF-MS, matrix assisted laser desorption ionization-time of flight-mass spectrometric; 1-DE, one-dimensional electrophoresis; 2-DE, two-dimensional electrophoresis; 2D-DIGE, two-dimensional differential gel electrophoresis; SELDI-TOF-MS, surface-enhanced laser desorption/ionization time-of-flight mass spectrometry; LC-MS/MS, liquid chromatography-tandem mass spectrometry; CPLL, combinatorial peptide ligand libraries technique; CSF, classical swine fever; NAFLD, nonalcoholic fatty liver disease.

\subsection{Monitoring of Animal Welfare}

The expression "animal welfare" indicates their physical and psychological wellbeing. The assessment of animals' wellbeing actually relies on behavioral tests (for most farm animals) which are easy to perform, or on measurement of stress markers like cortisol, also easy to measure but panels of biomarkers to associate each stress condition to physical and psychological state are desirable.

As described below, considerable experimental work, based on proteomics of farm animal serum, has been performed in order to assess the animals' welfare by monitoring stressful states associated with their farming, food safety patho-physiological state and reproduction conditions. At present, these protein markers donot replace older routinely tests because they have yet to be validated.

Farms with insufficient space and difficult environments can stimulate a constant stress condition that alters the activity of the pituitary-adrenal axis with relapses on behavior, reproduction and food product quality [56-58]. 
To this purpose, different farm animal species represented by pig, cow and fish were studied. By using 2D-DIGE, immunoblotting, and MS technologies, Marco-Ramell et al. [37] assessed the validity of traditional stress biomarkers in pigs housed at different densities, identifying the actin as a novel potential stress biomarker and proposing cholesterol, pig-major acute phase protein, oxidative stress marker and cortisol as a molecular profile of the stress conditions in pigs.

Subsequently, with the same aim, the authors identified antioxidant enzymes, such as glutathione peroxidase, $\alpha 2$ Heremans Schmid glycoprotein, cholesterol, and fecal corticosterone, as novel potential biomarkers for monitoring the adaptation process of Bruna cows to difficult environments [22]. Moreover, Liu et al. [50], for the first time, described the $N$-glycans level in salmon serum (Salmo salar) exposed to long-term handling stress (15 s out of the water daily, for four weeks), compared with fish control sera. The results showed that the $83 \%$ of $N$-glycans in salmon serum is formed by mono-acetylated sialic acids, and the $O$-acetylation pattern of sialic acids was indeed altered by the handling stress. Finally, Jiang et al. [51] and Kumar et al. [52] revealed that plasma lysozyme and angiotensin carboxypeptidase activities were significantly enhanced in fish transferred from hypoosmotic to hyperosmotic solution.

Many other proteomic approaches were applied on cow serum samples to obtain results able to assess the bovine welfare. It is well known that performance enhancing agents are illegally used in animals, in order to increase lean meat production; however, these illicit substances could produce serious state of stress in the meat animals. Owing to the very low dosage and the use of uncharacterized new chemical agents, the identification of these molecules by conventional analytical approaches is challenging. This scenario encouraged a strong interest in the development of new and efficient molecular biomarkers for the detection of growth promoting agents in animals raised for meat production. In this regard, Della Donna et al. [23] developed a multivariate MALDI-TOF-MS proteomics platform, creating reproducible protein mass profiles from small volumes of serum samples, to identify calves undergoing illicit treatments. This pioneering work provided evidence of the potential application of MALDI-TOF-MS proteomic profiling in the food safety control. Xia et al. [24] investigated the plasma proteome of cows affected by milk fever (a disease of dairy cows characterized by reduced blood calcium levels, causing a state of stress and production of low quality milk) and identified the pathophysiological modulations of angiotensin, endopin 2B, albumin, fibrinogen $\beta$ chain and IgG heavy-chain $C$-region by using DIGE technology, followed by MALDI-TOF proteins identifications.

Cairoli et al. [25] highlighted modulations in the serum proteome of heifers, to improve management of their peripartum period and, finally, for in-depth bovine plasma proteome characterization, Henning et al. [26] applied CPLL technology and three complementary fractionation strategies (SDS-PAGE, gel-free protein isoelectrofocusing or gel-free peptide isoelectrofocusing), identifying 480 bovine plasma proteins.

The application of proteomic technologies on horse serum samples produced different results in order to monitor equine welfare. Moore et al. [46] evaluated the effects of the ingestion of the Senecio jacobea (a poisonous weed ragwort very dangerous in hay) by horses, highlighting the presence of pyrrolizidine alkaloid toxins that are subsequently metabolized to cytotoxic pyrroles, which can bind proteins. They showed the modifications of equine plasma proteins with pyrrolic metabolites using sodium dodecyl sulfate polyacrylamide gel electrophoresis (SDS-PAGE), and MS as 
proteomics platforms. This model could be a new proteomic approach aimed at identifying potential protein biomarkers of ragwort exposure in horses and other livestock.

By establishing equine serum protein databases and by collecting knowledge on proteome modulation during diseases, Miller et al. [47] identified different serum proteins from different horse breeds by using 2-DE and MALDI-TOF-MS. Conversely, Henze et al. [48] evaluated the differences in serum proteome profiles of horses, donkeys, and mules, using SELDI-TOF technology and highlighted changes in posttranslational modifications (PTMs) of the protein transthyretin by using immunoprecipitation and MALDI-TOF-MS.

Fish serum proteomic studies also produced important results. Brunt et al. [53] applied proteomic platforms based on 2-DE and MALDI-TOF-MS to analyze the alterations of protein profiles in serum of rainbow trout (Oncorhynchus mykiss, Walbaum), as a measure of the acute phase response to probiotics Aeromonas sobria GC2 and Bacillus sp. JB-1, present in the feed. Wu et al. (2004) [54] applied 2-DE with Tris-tricine gel system, peptide mass fingerprinting and MS/MS proteomic platforms to characterize the alterations in serum of low molecular weight acute phase proteins in loach after injury. In this experimental work, the authors highlighted the up-regulation of C-reactive protein and gastrin 71, the down-regulation of apolipoprotein and the disappearance of parvalbumin in serum from loach following injury with respect to control fish.

Finally, serum proteomic strategies have been applied by Huang et al. [42] in order to investigate the changes in proteome of laying hens at different developmental stages.

\subsection{Monitoring of Diseases}

Infectious diseases of animals are caused by pathogenic agents, such as bacteria, viruses, protists, and represent a major health threat.

Proteomic strategies have been applied on serum samples from bovine, ovine, swine, poultry, equine, and fish, to identify novel biomarkers for early diagnosis, prognosis, assessment and treatment monitoring of infectious diseases and to best understand their pathogenetic mechanisms and develop new treatments.

\subsubsection{Bovine Serum Proteomics}

One of the first samples of applied infectious proteomic study is the analysis of bovine mastitis that causes decreased milk production and, therefore, economic damage to the industry. Bovine mastitis is an infectious disease, whose transmission is strongly influenced by factors related both to animals (breed, parity, stage of lactation, production level, morphological characteristics) and farming conditions (farm hygiene, presence of litter, conditions and maintenance of the milking machine, correct milking execution). Some bacteria involved in mastitis can cause serious human diseases. Moreover, treatment of the animal disease can result in the presence of antibiotic residues in milk, causing allergic sensitization or inducing antibiotic resistance in humans. The proteomic differential approach has been used in several works obtaining appreciable results [27]. In particular, the analysis of health bovine serum and mastitis serum by using 2-DE followed by MALDI-TOF-MS, allowed the authors to obtain disease-specific protein maps to monitor the course of the disease and the response to treatment [28]. 
Other bovine infectious diseases, that have been characterized by a proteomic approach, are tuberculosis, Johne's disease (JD) and besnoitiosis. The bovine tuberculosis represents a highly prevalent zoonotic infection in cattle worldwide, caused by the intracellular bacterium Mycobacterium bovis (MB). Looking for an early detection of MB infection, Seth et al. [29] identified new protein biomarkers using iTRAQ on cattle serum samples infected with either MB or Mycobacterium paratuberculosis (MP).

JD is a worldwide common and economically relevant chronic inflammatory pathology of the small intestine of ruminants caused by Mycobacterium avium subspecies paratuberculosis (MAP). Moreover, numerous technological approaches currently available for JD diagnosis have a limited sensitivity. To this purpose, You et al. [30] applied CPLL, 2D-DIGE, and LC-MS/MS, to detect protein biomarkers of MAP infection in cows.

Finally, Bovine besnoitiosis (BB), a re-emergent disease in Europe, also present in Africa and Asia, is caused by the cyst-forming apicomplexan parasite Besnoitia besnoiti and is responsible for severe economic losses. However, the disease molecular mechanisms and parasite biology have still to be clarified. García-Lunar et al. [31] conducted a proteomic study to describe the proteome and immunome of the tachyzoite stage of BB using 2-DE, immunoblotting and MALDI-TOF/TOF MS.

They found several proteins, five of which were cross-reactive antigens between BB and $N$-caninum. They also investigated both the relevant biological processes and the host immune response associated with the parasite infection.

\subsubsection{Ovine Serum Proteomics}

Staphylococcus aureus mastitis can also adversely affect the production of sheep's milk.

Unfortunately, antibiotic treatment and prophylactic measures, including the development of an effective vaccine, so far have proven to be ineffective tools for the control of this disease. In this regard, Vytvytska et al. [32] and Le Maréchal et al. [33] applied 2-DE, immunoblotting and MALDI-TOF-MS proteomic approaches for the identification of novel staphylococcal antigens for rational vaccine design.

Zhong et al. [34] applied SELDI MS, SDS-PAGE, and LC-MS/MS technologies on sheep whole serum infected with MAP and identified transthyretin and $\alpha$-haemoglobin as putative biomarkers.

Some papers have been published on the characterization of the early detection of the immunological responses in viral and bacterial infections in sheep using SELDI-TOF, 2-DE and MALDI-TOF/TOF MS techniques on sera. The results showed different up- and down-regulated proteins, related to controls that could be potential biomarkers $[35,36]$.

\subsubsection{Swine Serum Proteomics}

Sun et al. [38] analyzed the serum proteome modulations in pigs infected with classical swine fever virus, using 2-D DIGE followed by MALDI-TOF-MS or LC-MS/MS. They identified 10 differentially expressed protein spots, potentially biomarkers for the early diagnosis of the disease. Another serious infectious disease is foot-and-mouth disease (FMD) that affects cloven-hoofed animals. The virus causes high fever and produces blisters inside the mouth and on the feet that may break, thus causing lameness. FMD can affect humans but it is not dangerous for their health. Liu et al. [39] reported the 
first qualitative serum proteomic analysis from pigs before and after induced infection by FMD virus using LC-MS/MS. They developed novel drug targets and new biomarkers for care and early diagnosis of FMD and elucidated some mechanisms of the FMD virus pathogenesis.

Some human diseases can also be studied in animal models in order to compare the results with those from human studies and best understand the pathogenetic mechanisms and develop new treatments. The main limitation of this approach is related to the transferability of data between animal species. In fact, homologous proteins could have different post translational modifications and, therefore, different interaction protein patterns and biological functions, too.

Nonalcoholic fatty liver disease (NAFLD) is a common chronic disorder that occurs in the absence of significant alcohol abuse [59]; its pathogenesis has not yet been fully clarified. Appropriate animal models can help analyze the molecular mechanisms and identify new biomarkers for early detection and therapy monitoring. In this regard, Lee et al. [40] and Bell et al. [41] created a nutritional model of NASH (non-alcoholic steatohepatitis) and metabolic syndrome in miniature Ossabaw pigs very similar to human NASH and, using label-free quantitative proteomics approach, they assessed the modulation of serum proteomic profiles in animal and human NAFLD. The authors recommend the use of this pig model to improve knowledge on NASH and related metabolic abnormalities.

\subsubsection{Poultry Serum Proteomics}

Each year the poultry industry suffers from consistent financial losses due to Colibacillosis disease, caused by an avian pathogenic Escherichia coli (APEC) that mainly affects broiler chickens resulting in septicemia and death. Using a proteomic approach, Tyler et al. [43] characterized specific proteins possibly involved in serum resistance of APEC isolates. In this study, the serum proteins were purified and separated by 2-DE approach; subsequently, ten protein spots, corresponding to eight differentially expressed proteins (some of them previously associated with E. coli virulence) were selected and characterized by LC-MS/MS. This pivotal study represented the precursor of future proteomic applications to identify the key players in serum resistance of APEC.

Later, Li et al. [44], using SDS-PAGE and MALDI-TOF/TOF-MS, compared the APEC proteome from human and avian sera, to determine growth in different host species and assess different survival strategies. In response to both human and avian sera, proteins contributing to active iron scavenging were up-regulated in APEC. Interestingly, these data support the concept that both human and avian sera are iron-limited environments.

Coccidiosis disease is characterized by destruction of the mucosa and is caused by Eimeria species, a protozoan responsible for a host- and infection site-specific intestinal disease. Two-DE, followed by MALDI-TOF/TOF MS were used to assess the serum proteome of broilers, after Eimeria acervulina inoculation. The identification of proteins that significantly changed in response to the infection allowed to highlight host response to coccidiosis and identify diagnostic and pharmacological targets [45].

\subsubsection{Equine Serum Proteomics}

Proteomic strategies based on 2D-DIGE and MALDI-TOF approaches have been applied on healthy and uveitis-affected horse serum samples, with the aim of identifying seven biomarker candidates for the diagnosis of autoimmune uveitis [49]. 


\subsubsection{Fish Serum Proteomics}

The mass spectrometry based proteomics have been applied by Liu et al. [55] to evaluate the first heterogeneous interactome between shrimp serum proteins and Vibrio parahaemolyticus outer membrane proteins; their results indicated that a complex network is formed when microbes invade the host.

\section{Conclusions and Future Perspectives}

Proteomics could help evaluate the farm animal welfare, reduce the risk of zoonoses and improve quality and safety of animal products while reducing financial losses.

During the last decade, the development of standard pre-analytical sample treatments, MS-based technologies and data processing systems for data management, have designated proteomics as a major platform to interrogate the plasma/serum proteome for discovery of next-generation biomarkers in the human and veterinary field. Due to the high number of serum proteins that may be simultaneously investigated, this approach is faster than ELISA and PCR techniques. The high initial investment required to buy the equipment represents a major limitation to a more widespread use of the technique. However, the costs involved are rapidly falling, thus, favoring its purchase. New proteomic technologies may dramatically improve discovery of next-generation biomarkers supporting diagnosis and monitoring of a variety of diseases in human and farm animals.

\section{Supplementary Materials}

Supplementary Figure can be found at http://www.mdpi.com/1422-0067/15/9/15396/s1.

\section{Acknowledgments}

This work was supported by San Camillo Hospital, Treviso, Italy Fellowship Program to Maurizio Muraca; Ministry of Health, Ricerca Corrente (RC201402G003251) to Lorenza Putignani. We especially thank Andreina Santoro for the careful revision of the English language and Andrea Petrucca for manuscript editing and critical discussion.

\section{Author Contributions}

Francesco Di Girolamo designed the review article and drafted the manuscript; Isabella Lante, Alfonsina D'Amato and Marta Muraca contributed to draw up the manuscript; Fabrizio Signore helped us to completely revise the manuscript; Lorenza Putignani gave her valuable support in the critical revision of the manuscript and conceptual content. All the authors read and approved the final manuscript.

\section{Conflicts of Interest}

The authors declare no conflict of interest. 


\section{References}

1. Doherty, M.K.; Beynon, R.J.; Whitfield, P.D. Proteomics and naturally occurring animal diseases: Opportunities for animal and human medicine. Proteomics Clin. Appl. 2008, 2, 135-141.

2. Ceciliani, F.; Eckersall, D.; Burchmore, R.; Lecchi, C. Proteomics in veterinary medicine: Applications and trends in disease pathogenesis and diagnostics. Vet. Pathol. 2014, 51, 351-362.

3. Anderson, N.L.; Anderson, N.G. The human plasma proteome: History, character, and diagnostic prospects. Mol. Cell Proteomics 2002, 1, 845-867.

4. Introduction to Mass Spectrometry. Available online: http://www.medicine.virginia.edu/research/ cores/biomolec/ProteinAnalysisbyMassSpectrometry/Intro\%20to\%20Mass $\% 20 \mathrm{Spec} \% 20 \mathrm{Course} \% 2$ 0UVa\%2020100518.pdf (accessed on 1 September 2014).

5. Fang, X.; Zhang, W.W. Affinity separation and enrichment methods in proteomic analysis. J. Proteomics 2008, 71, 284-303.

6. Righetti, P.G.; Boschetti, E. The ProteoMiner and the FortyNiners: Searching for gold nuggets in the proteomic arena. Mass Spec. Rev. 2008, 27, 596-608.

7. Boschetti, E.; Lomas, L.; Citterio, A.; Righetti, P.G. Romancing the "hidden proteome", anno domini two zero zero seven. J. Chromatogr. A 2007, 1153, 277-290.

8. Boschetti, E.; Righetti, P.G. The art of observing rare protein species in proteomes with peptide ligand libraries. Proteomics 2009, 9, 1492-1510.

9. Gundry, R.L.; White, M.Y.; Nogee, J.; Tchernyshyov, I.; van Eyk, J.E. Assessment of albumin removal from an immunoaffinity spin column: Critical implications for proteomic examination of the albuminome and albumin-depleted samples. Proteomics 2009, 9, 2021-2028.

10. Zhi, W.; Purohit, S.; Carey, C.; Wang, M.; She, J.X. Proteomic technologies for the discovery of type 1 diabetes biomarkers. J. Diabetes Sci. Technol. 2010, 4, 993-1002.

11. Walther, T.C.; Mann, M. Mass spectrometry-based proteomics in cell biology. J. Cell Biol. 2010, 190, 491-500.

12. Pan, C.; Xu, S.; Zhou, H.; Fu, Y.; Ye, M.; Zou, H. Recent developments in methods and technology for analysis of biological samples by MALDI-TOF-MS. Anal. Bioanal. Chem. 2007, 387, 193-204.

13. Rodríguez-Suárez, E.; Whetton, A.D. The application of quantification techniques in proteomics for biomedical research. Mass Spectrom. Rev. 2013, 32, 1-26.

14. Unlü, M.; Morgan, M.E.; Minden, J.S. Difference gel electrophoresis: A single gel method for detecting changes in protein extracts. Electrophoresis 1997, 18, 2071-2077.

15. Gygi, S.P.; Rist, B.; Gerber, S.A.; Turecek, F.; Gelb, M.H.; Aebersold, R. Quantitative analysis of complex protein mixtures using isotope-coded affinity tags. Nat. Biotechnol. 1999, 17, 994-999.

16. Ross, P.L.; Huang, Y.N.; Marchese, J.N.; Williamson, B.; Parker, K.; Hattan, S.; Khainovski, N.; Pillai, S.; Dey, S.; Daniels, S.; et al. Multiplexed protein quantitation in Saccharomyces cerevisiae using amine-reactive isobaric tagging reagents. Mol. Cell. Proteomics 2004, 3, 1154-1169.

17. Old, W.M.; Meyer-Arendt, K.; Aveline-Wolf, L.; Pierce, K.G.; Mendoza, A.; Sevinsky, J.R.; Resing, K.A.; Ahn, N.G. Comparison of label-free methods for quantifying human proteins by shotgun proteomics. Mol. Cell Proteomics 2005, 4, 1487-1502. 
18. Issaq, H.J.; Veenstra, T.D.; Conrads, T.P.; Felschow, D. The SELDI-TOF MS approach to proteomics: Protein profiling and biomarker identification. Biochem. Biophys. Res. Commun. 2002, 292, 587-592.

19. UniProt-GOA. Available online: http://www.ebi.ac.uk/GOA/newto (accessed on 27 August 2014).

20. Balakrishnan, R.; Harris, M.A.; Huntley, R.; van Auken, K.; Cherry, J.M. A guide to best practices for Gene Ontology (GO) manual annotation. Database 2013, 9, bat054.

21. Gene Ontology Consortium. Available online: http://beta.geneontology.org/ (accessed on 27 August 2014).

22. Marco-Ramell, A.; Arroyo, L.; Saco, Y.; García-Heredia, A.; Camps, J.; Fina, M.; Piedrafita, J.; Bassols, A.J. Proteomic analysis reveals oxidative stress response as the main adaptative physiological mechanism in cows under different production systems. Proteomics 2012, 75, 4399-4411.

23. Della Donna, L.; Ronci, M.; Sacchetta, P.; Di Ilio, C.; Biolatti, B.; Federici, G.; Nebbia, C.; Urbani, A. A food safety control low mass-range proteomics platform for the detection of illicit treatments in veal calves by MALDI-TOF-MS serum profiling. J. Biotechnol. 2009, 4, 1596-1609.

24. Xia, C.; Zhang, H.Y.; Wu, L.; Xu, C.; Zheng, J.S.; Yan, Y.J.; Yang, L.J.; Shu, S. Proteomic analysis of plasma from cows affected with milk fever using two-dimensional differential in-gel electrophoresis and mass spectrometry. Res. Vet. Sci. 2012, 93, 857-861.

25. Cairoli, F.; Battocchio, M.; Veronesi, M.C.; Brambilla, D.; Conserva, F.; Eberini, I.; Wait, R.; Gianazza, E. Serum protein pattern during cow pregnancy: Acute-phase proteins increase in the peripartum period. Electrophoresis 2006, 27, 1617-1625.

26. Henning, A.K.; Groschup, M.H.; Mettenleiter, T.C.; Karger, A. Analysis of the bovine plasma proteome by matrix-assisted laser desorption/ionisation time-of-flight tandem mass spectrometry. Vet. J. 2014, 199, 175-80.

27. Turk, R.; Piras, C.; Kovačić, M.; Samardžija, M.; Ahmed, H.; de Canio, M.; Urbani, A.; Meštrić, Z.F.; Soggiu, A.; Bonizzi, L.; et al. Proteomics of inflammatory and oxidative stress response in cows with subclinical and clinical mastitis. Proteomics 2012, 75, 4412-4428.

28. Alonso-Fauste, I.; Andrés, M.; Iturralde, M.; Lampreave, F.; Gallart, J.; Alava, M.A.J. Proteomic characterization by 2 -DE in bovine serum and whey from healthy and mastitis affected farm animals. Proteomics 2012, 75, 3015-3030.

29. Seth., M.; Lamont, E.A.; Janagama, H.K.; Widdel, A.; Vulchanova, L.; Stabel, J.R.; Waters, W.R.; Palmer, M.V.; Sreevatsan S. Biomarker discovery in subclinical mycobacterial infections of cattle. PLoS One 2009, 4, e5478.

30. You, Q.; Verschoor, C.P.; Pant, S.D.; Macri, J.; Kirby, G.M.; Karrow, N.A. Proteomic analysis of plasma from Holstein cows testing positive for Mycobacterium avium subsp. paratuberculosis (MAP). Vet. Immunol. Immunopathol. 2012, 148, 243-251.

31. García-Lunar, P.; Regidor-Cerrillo, J.; Gutiérrez-Expósito, D.; Ortega-Mora, L.; Alvarez-García, G. First 2-DE approach towards characterising the proteome and immunome of Besnoitia besnoiti in the tachyzoite stage. Vet. Parasitol. 2013, 195, 24-34.

32. Vytvytska, O.; Nagy, E.; Blüggel, M.; Meyer, H.E.; Kurzbauer, R.; Huber, L.A.; Klade, C.S. Identification of vaccine candidate antigens of Staphylococcus aureus by serological proteome analysis. Proteomics 2002, 2, 580-590. 
33. Le Maréchal, C.; Jan, G.; Even, S.; McCulloch, J.A.; Azevedo, V.; Thiéry, R.; Vautor, E.; le Loir, Y.J. Development of serological proteome analysis of mastitis by Staphylococcus aureus in ewes. Methods Microbiol. 2009, 79, 131-136.

34. Zhong, L.; Taylor, D.; Begg, D.J.; Whittington, R.J. Biomarker discovery for ovine paratuberculosis (Johne's disease) by proteomic serum profiling. Comp. Immunol. Microbiol. Infect. Dis. 2011, 34, $315-326$.

35. Zhong, L.; Taylor, D.L.; Whittington, R.J. Proteomic profiling of ovine serum by SELDI-TOF MS: Optimisation, reproducibility and feasibility of biomarker discovery using routinely collected samples. Comp. Immunol. Microbiol. Infect. Dis. 2010, 33, 47-63.

36. Chiaradia, E.; Avellini, L.; Tartaglia, M.; Gaiti, A.; Just, I.; Scoppetta, F.; Czentnar, Z.; Pich, A. Proteomic evaluation of sheep serum proteins. BMC Vet. Res. 2012, 25, 66.

37. Marco-Ramell, A.; Pato, R.; Peña, R.; Saco, Y.; Manteca, X.; Ruiz de la Torre, J.L.; Bassols, A. Identification of serum stress biomarkers in pigs housed at different stocking densities. Vet. J. 2011, 190, e66-e71.

38. Sun, J.F.; Shi, Z.X.; Guo, H.C.; Li, S.; Tu, C.C. Proteomic analysis of swine serum following highly virulent classical swine fever virus infection. Virol. J. 2011, 8, 107.

39. Liu, Y.; Zhang, K.; Zheng, H.; Shang, Y.; Guo, J.; Tian, H.; Lu, G.; Jin, Y.; He, J.; Cai, X.; et al. Proteomics analysis of porcine serum proteins by LC-MS/MS after foot-and-mouth disease virus (FMDV) infection. J. Vet. Med. Sci. 2011, 73, 1569-1572.

40. Lee, L.; Alloosh, M.; Saxena, R.; van Alstine, W.; Watkins, B.A.; Klaunig, J.E.; Sturek, M.; Chalasani, N. Nutritional model of steatohepatitis and metabolic syndrome in the Ossabaw miniature swine. Hepatology 2009, 50, 56-67.

41. Bell, L.N.; Lee, L.; Saxena, R.; Bemis, K.G.; Wang, M.; Theodorakis, J.L.; Vuppalanchi, R.; Alloosh, M.; Sturek, M.; Chalasani, N. Serum proteomic analysis of diet-induced steatohepatitis and metabolic syndrome in the Ossabaw miniature swine. Am. J. Physiol. Gastrointest. Liver Physiol. 2010, 298, 746-754.

42. Huang, S.Y.; Lin, J.H.; Chen, Y.H.; Chuang, C.K.; Chiu, Y.F.; Chen, M.Y.; Chen, H.H.; Lee, W.C. Analysis of chicken serum proteome and differential protein expression during development in single-comb White Leghorn hens. Proteomics 2006, 6, 2217-2224.

43. Tyler, C.D.; Lichti, C.F.; Diekman, A.B.; Foley, S.L. Evaluation of differentially expressed proteins following serum exposure in avian pathogenic Escherichia coli. Avian Dis. 2008, 52, 23-27.

44. Li, G.; Cai, W.; Hussein, A.; Wannemuehler, Y.M.; Logue, C.M.; Nolan, L.K.J. Proteome response of an extraintestinal pathogenic Escherichia coli strain with zoonotic potential to human and chicken sera. Proteomics 2012, 75, 4853-4862.

45. Gilbert, E.R.; Cox, C.M.; Williams, P.M.; McElroy, A.P.; Dalloul, R.A.; Ray, W.K.; Barri, A.; Emmerson, D.A.; Wong, E.A.; Webb, K.E. Eimeria species and genetic background influence the serum protein profile of broilers with coccidiosis. PLoS One 2011, 6, e14636.

46. Moore, R.E.; Knottenbelt, D.; Matthews, J.B.; Beynon, R.J.; Whitfield, P.D. Biomarkers for ragwort poisoning in horses: Identification of protein targets. BMC Vet. Res. 2008, 8, 4-30.

47. Miller, I.; Friedlein, A.; Tsangaris, G.; Maris, A.; Fountoulakis, M.; Gemeiner, M. The serum proteome of Equus caballus. Proteomics 2004, 4, 3227-3234. 
48. Henze, A.; Aumer, F.; Grabner, A.; Raila, J.; Schweigert, F.J. Genetic differences in the serum proteome of horses, donkeys and mules are detectable by protein profiling. J. Nutr. 2011, 1, $170-173$.

49. Zipplies, J.K.; Hauck, S.M.; Schoeffmann, S.; Amann, B.; Stangassinger, M.; Ueffing, M.; Deeg, C.A. Serum PEDF levels are decreased in a spontaneous animal model for human autoimmune uveitis. J. Proteome Res. 2009, 8, 992-998.

50. Liu, X.; Afonso, L.; Altman, E.; Johnson, S.; Brown, L.; Li, J. $O$-acetylation of sialic acids in $\mathrm{N}$-glycans of Atlantic salmon (Salmo salar) serum is altered by handling stress. Proteomics $\mathbf{2 0 0 8 ,}$ 8, 2849-2857.

51. Jiang, I.F.; Kumar, V.B.; Weng, C.F. Acute osmotic stress affects tilapia (Oreochromis mossambicus) innate immune responses. Fish Shellfish Immunol. 2008, 25, 841-846.

52. Kumar, V.B.; Jiang, I.F.; Yang, H.H.; Weng, C.F. Effects of serum on phagocytic activity and proteomic analysis of tilapia (Oreochromis mossambicus) serum after acute osmotic stress. Fish Shellfish Immunol. 2009, 26, 760-767.

53. Brunt, J.; Hansen, R.; Jamieson, D.J.; Austin, B. Proteomic analysis of rainbow trout (Oncorhynchus mykiss, Walbaum) serum after administration of probiotics in diets. Vet. Immunol. Immunopathol.2008, 121, 199-205.

54. Wu, Y.; Wang, S.; Peng, X. Serum acute phase response (APR)-related proteome of loach to trauma. Fish Shellfish Immunol. 2004, 16, 381-389.

55. Liu, X.; She, X.T.; Zhu, Q.F.; Li, H.; Peng, X.X. Heterogeneous interactome between Litopenaeus vannamei plasma proteins and Vibrio parahaemolyticus outer membrane proteins. Fish Shellfish Immunol. 2013, 34, 192-198.

56. Kornegay, E.T.; Nolter, D.R. Effect of floor space and number of pigs per pen on performance. Pig News Inf. 1984, 5, 23-33.

57. Kuhlers, D.L.; Jungst, S.B.; Marple, D.N.; Rahe, C.H. The effect of pen density during rearing on subsequent reproductive performance in gilts. J. Anim. Sci. 1985, 61, 1066-1069.

58. Meunier-Salaun, M.C.; Vantrimponte, M.N.; Raab, A.; Dantzer, R. Effect of floor area restriction upon performance, behavior and physiology of growing-finishing pigs. J. Anim. Sci. 1987, 64, 1371-1377.

59. Angulo, P. Nonalcoholic fatty liver disease. N. Engl. J. Med. 2002, 346, 1221-1231.

(C) 2014 by the authors; licensee MDPI, Basel, Switzerland. This article is an open access article distributed under the terms and conditions of the Creative Commons Attribution license (http://creativecommons.org/licenses/by/3.0/). 